Madrygal. Revista de Estudios Gallegos

ISSN: 1138-9664

\title{
Conversa á sombra con Luz Pichel
}

\section{Lidia Teixeiro $^{1}$}

Non se escolle o humor para recibir a unha visita, igual que tampouco a figueira escolle cando deixará quebrar as súas pólas por culpa do froito. Unha horta é coma unha casa, supoño, mentres Luz Pichel me guía polas estancias do seu fogar, e fálame tanto coma as paredes que falan. E déixame entrar. Vivir en Alén, viaxar a Alén, coidar en Alén. Antóllaseme, a pesar do mimo co que Luz trata a miña visita, unha grande responsabilidade. É o lugar da poeta.

No xardín, no seu recanto favorito, ao pé dun acivro e compartimos unhas horas. Ademais das palabras, na gravación que hoxe transcribo entre dúas terras, viaxando, quedaron por sempre inmortalizados entre as súas risadas, os cantos dos paxaros.

-L.T.: A primeira pregunta que pensei, de que non fala Luz Pichel nas entrevistas?

-L.P.: Eu son moi faladeira pero nas entrevistas, e en público, non me gusta falar da miña familia. Non dos ancestros, non da familia que foi, senón da familia presente. Penso que non ten interese para ninguén. Así como falar dos meus pais si que ten interese para a miña obra, falar dos meus fillos, das miñas fillas, dos meus netos...

-L.T.: Noutra conversa, mencionárasme unha data do teu pasado, 1957. Lémbrache algo en especial, da infancia?

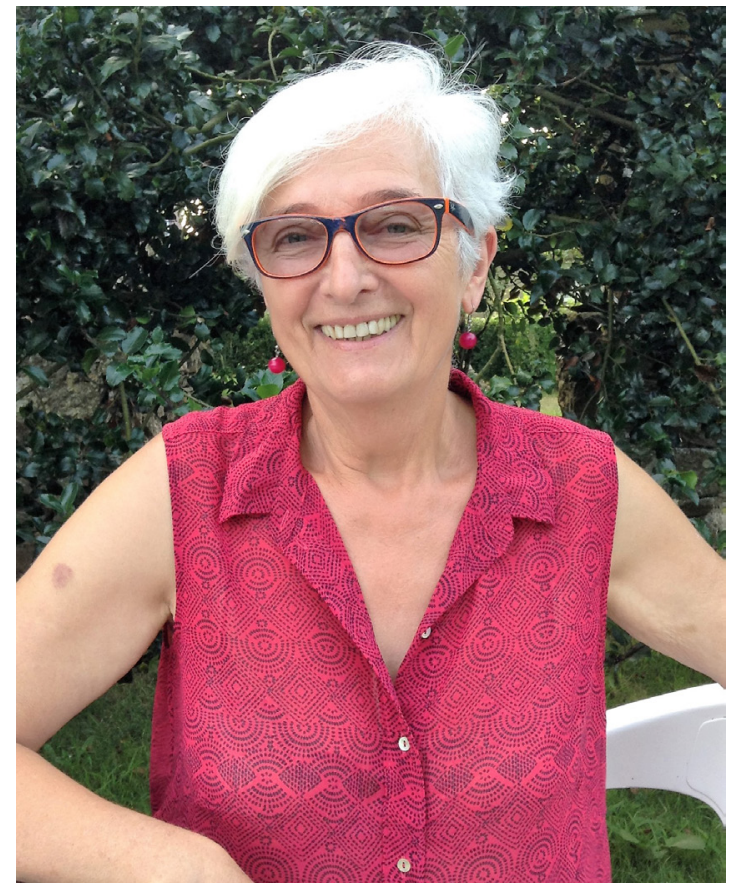

(fotografía: Lidia Teixeiro)

-L.P.: Eu teño momentos infantís moi duros. 1957 foi o ano en que retornou definitivamente miña nai. Quedara con miña irmá, unha rapaza de catorce anos, quen me criou coma se fora unha bonequiña. Cando veu por segunda vez, eu tiña dez anos. Para min foi moi traumático, moi dificil.

Universidad Complutense de Madrid, Departamento de Filología Románica, Filología Eslava y Lingüística General; Centro de 


\section{-L.T.: Non te criaches con ela?}

-L.P.: Tiña catro anos cando se marchou. A primeira vez que veu, veu para a voda de miña irmá. Miña nai viña como a ocupar o seu sitio e a apartar a miña irmá. Eu vino así, claro, e non me gustaba, Pretendeu ensinarme a facer as camas, pero eu sabía como se tiñan que facer, como me ensinara miña irmá, sabes? Había un rexeitamento. Tamén pasaba que meu pai a poñía a un lado coma se fose a princesa que viña a transformar o mundo. A realidade era outra, miña nai era unha muller normal, moi queimada, pasárao moi mal e eu sentía que entre ela e eu non había feeling, non había nada.

\section{-L.T.: Que duro...}

-L.P.: Moito. Moito, porque apartarte de sete fillos e ir traballar fóra non se fai sen pagar algo. Coido que hai que facerse moita coraza para resistir. Foi un regreso complicado.

\section{-L.T.: Pero non hai xuízo pola túa parte.}

-L.P.: Non non, moito menos agora que pasou o tempo. Foi difícil que houbera unha comunicación próxima entre ela e mais eu até os últimos anos, cando a levei a vivir comigo ao morrer meu pai. El non se podía sacar de aquí, estaba todo o día cortando na leña, facendo cousas, estaba moi ben. Pero cando faltou, ela, que non se movía, aceptou moi contenta vivir comigo en Madrid. E, a pesar de que xa estaba moi mal, alí si que houbo unha aproximación.

Agora teño unha consideración de miña nai moito mellor, foi mais ben unha vítima. Xustifícoa totalmente. Mais, naquel momento eu víaa así. E molestábame moito cando, acabada de chegar, falaba castelán.

\section{-L.T.: Contigo falaba en castelán?}

-L.P.: Aquí todo o mundo falaba cos fillos en galego, pero cando veu de Venezuela algunhas veces falaba castelán. Según con quen se topara, sabes? Miña nai viña modernizada. Viña de criar nenos onde se trataba de ti aos pais. Ela quixo que a trataramos así e meu pai non, tonterías, pero acabamos por facelo igualmente, porque ela insistía. Todo iso pasoulle pronto e volveuse acomodar á vida e á lingua da aldea.

\section{-L.T.: Sempre tiveches máis relación co} teu pai? Como era?

-L.P.: Podía ser moi duro ás veces, e outras veces amoroso, eu era o seu olliño dereito, a nena, a pequena de sete irmáns. Levábame sempre no carro, que para min era o pracer maior do mundo. Tiña un xogo comigo, cantaba unha copliña e dicíame: «tes que adiviñar a última palabra». Sabíaas en galego, en castelán, mesturábaas todas, dicía que algunhas as inventaba el; non sei se sería verdade ou non. Doutras contaba: «cantábana así en tal sitio pero sóbralle unha sílaba, sóbralle algo». E efectivamente, sobráballe unha sílaba. Eu adiviñáballas todas. Eran ripios, rimillas de canción, moi fáciles, pero el estaba moi orgulloso diso. Mimábame moito. Vivín moi estimulada, consideraba el que era moi lista. Cando xa estaba nas monxas e regresaba, íamos á tenda de Lalín a comprar e dicía: "esta é a miña filla e estas as súas notas». Era xenial, vital, moi creativo, estaba todo o día facendo música. Non era músico pero cantaba e tocaba moi ben as castañolas e moi ben a pandeireta, collía un par de culleres e facía virguerías, bailaba coxo, bailaba a muiñeira que era un artista.

A miña nai tocáballe ser a seria e dicíalle «deixarás eses chistes algunha vez?»[risas]. El contaba chistes de todo, e entón ela berráballe. Cando ela xa non se podía mover, el respondíalle: "se saíses de detrás desa cociña e te puxeses a facer algo». E ela: «Ai, pero, traballa, queres traballar? Traballa, que che ha quedar todo aquí»».

\section{-L.T.: A quen cres que te pareces máis?}

-L.P.: A meu pai, en todo. Era supertraballador, moito máis apegado á terra, identifícome moito con el. E iso que agora, fisicamente, a medida que vou sendo maior, hai veces que me miro ao espello e estou vendo a miña nai.

\section{tudando?}

-L.P.: Eu estudei porque me pagaron os meus estudos os meus irmáns. Se non, non podería. Miña nai quería que quedara na casa, mandoume coser a un taller que había por aquí e eu iba encantada, gustábame moito. Ao final do curso preguntoume se me gustaba e eu díxenlle que si. «Entón non vas ir estudiar». «Si que vou» [risas]. E fun. Quería que quedara na casa e terme máis cerca.

\section{-L.T.: Estudaches en Santiago de Com- postela?}

-L.P.: Si. Primeiro en Lugo, nas monxas, e despois en Santiago na Universidade, até terceiro. Despois de terceiro foi cando me 
enamorei e larguei para Madrid. Aos dez ou quince días de coñecer ao meu mozo. Díxenlles que me deran unha bolsa para ir estudar a Madrid. Non dependía economicamente deles xa, porque cando empecei a Universidade empecei a dar clases particulares e vivía pola miña conta. Conteilles esa trola para que me deixaran marchar. E desde que cheguei, escribinlles unha carta longa e conteilles a verdade. Miña nai contestoume: «Siempre hiciste lo que quisiste y vas a seguir haciéndolo. Pero no me llegues a casa con un hijo». iso?

-L.T.: [silencio] Que lle contestaches a

-L.P.: Nada. Que lle vas a contestar... Era moi comprensible ese medo nunha muller de aquela época. Súa nai, miña avoa, sufrirá a "infamia" de ser unha nai solteira. Acabei a carreira na UCM, fixen dous anos alí, cuarto e quinto.

\section{-L.T.: E marchastes para Inglaterra.}

-L.P.: E marchamos para Inglaterra, estivemos dous anos alí.

-L.T.: A biografía que acompaña o libro El Pájaro Mudo y otros poemas, a petición de Manuel Romero, remata en 2003. Que habería que engadir?

-L.P.: Pois habería que engadir moito, non? Os netos, a xubilación. Retireime no ano 2008 e ese mesmo verán, a miña filla Celia xuntouse comigo no retiro, convidoume a unha cervexa, e díxome que tiña que contarme unha cousa moi importante, que ía ter un neno.

-L.T.: Hai tempo para todo. Sacaches máis tempo para o que che apetecía.

-L.P.: Si, claro. Aínda que é importante que non tomemos a poesía, e eu diría a escritura en xeral, como un medio de vida, nunca. Primeiro porque non che dá para vivir, pero, sobre todo, porque se te fas esa ilusión xa estás condenado, tes que escribir para vender. Coñecín a algunha persoa moi exposta a ese perigo e que sufriu moito por iso. Por empezar moi novas acaban pensando que van a poder vivir de escribir e despois non é así. A frustación é tremenda e acaban escribindo peor. Non son libres, teñen que escribir o que o comercio esta pedindo.

-L.T.: Ti compartes moito do teu proceso de creación, non parece ser un proceso solitario.
-L.P.: Non, non, a min non me importa nada compartir. É mais, eu leo os poemas á xente antes de estar publicados; dinme cousas que entendo e valoro. Non teño esa cousa da obra.

Cando estaba recén divorciada levábao moi mal, moi mal sobre todo cando quedaba soa. Recordo un sabado que tiña que ir á compra. Vou á compra, cargo o carriño, chorando, pago no caixeiro, chorando, todo chorando. Entro nunha librería que había alí e compro un libro, La lluvia amarilla, de Julio Llamazares. «Non sei para que compro un libro se total non o vou ler». Tireino así para un lado e ao día seguinte, que era domingo, collín un café, metinme na cama, púxenme a lelo e déronme as dúas da tarde e eu estaba feliz. «Non é tan malo que as rapazas se vaian co pai» [risas]. Sabes esa sensación de estar nun mundo, centrada? Quizais esa sexa a expresión de cando escribes. Estás moi concentrado. Tanto que é pracenteiro, que todo o teu organismo, todo o teu corpo, toda tua mente están aí, equilibrados, están ben. É, supoño, coma unha droga, que non me drogo máis que así.

Creo que teño facilidade para me abstraer, necesito tempo. Cando escribín Casa pechada, non tiña, nada! Estaba aquí [en Alén], isto era un desorde impresionante e eu quería deixar todo moi ben para poder levarme a mamá e que vira que a casa quedaba ben, que iamos volver. Traballaba todo o día limpando, ordenando, preparando as cousas. Chegaba a noite e escribía sobre a experiencia do día, cansadísima, esgotada, pero escribía. E pasábao fenomenal. Saía, fluía; a dedicación non é necesario que teña que ser seguido.

Normalmente non invirto moito tempo no que é a primeira versión dun libro. Gasto tempo despois, pero na primeira versión non. É a da inspiración e non é moi longa, vou correndo é fágoa nun instante. $\mathrm{O}$ resultado é algo que vén despois da inspiración, é algo moi posterior. Despois, dándolle voltas, veñen outros momentos, en que che fan cambiar «Ai, pero que puxen aquí se aquí o que hai que poñer é isto?». Ese é outro momento de inspiración que é froito do traballo. Traballo moito a poesía, e tiña que traballala máis. É coma o pintor que vai ao campo e fai un trazo e ten unha árbore. É mentira. Despois chega á súa casa, séntase e traballa. Puro traballo: isto aquí non soa ben, aquí hai que cambiar esta palabra por esta... son cousas que xa vas mellorando. 


\section{-L.T.: E hai que atreverse, non?}

-L.P.: Si , hai que ser valentes. Coa poesía hai que lanzarse. Esixe compromiso e, se non o tes, repites libro, repites forma, copias de ti mesmo, e abúrreste!

\section{-L.T.: Divírteste cando escribes?}

-L.P.: Moito, moito, moitísimo.

\section{-L.T.: Pero non escribes para divertirte!}

-L.P.: Tamén escribo para divertime. Descubrir que podía escribir así, que a xente podería lerme, dunha maneira constante, foi como entrar noutro mundo. Nun mundo, entre outras cousas, divertido. E pracenteiro. É difícil dicir que é divertido porque hai veces que non o pasas moi ben... pero hai xente que di que sofre moitísimo cando escribe e eu non. Eu pásoo moi ben non sendo cando hai algo que queres poñer e non acabas de encontrar a maneira. Mais, cando encontras, pola contra, é marabilloso. Sintes... Eu penso que todo acto creativo, cando verdadeiramente entras nel, libera. Libérate do tempo, dáche igual o espazo, non importa se che doe a ciática, non tes calor, non tes frío, estás ben. Iso pódese sentir escribindo, pódese sentir lendo, unha sensación de estar ben.

-L.T.: Que prefires, escribir ou recitar? Que te lean ou que te escoiten?

-L.P.: Gústame máis que me lean a que me escoiten; sempre o paso un pouco mal. Hai un ego, non cabe dúbida, que desenvolves cando estás recitando, pero ao mesmo tempo, hai uns nervios. Nunca sabes como che vai saír, tes medo a como serás acollida pola xente, pode resultar negativo, pode haber xente malintencionada que faga un comentario que che doia... Todo iso hai que aprendelo e leva moito tempo. A lectura é mais repousada, enténdese mellor cando a les... pero o feito de escoitar a poesía tamén me interesa porque te enteras tamén de cousas que non te enteras cando les.

-L.T.: A min paréceme que a túa obra cambia moito na lectura que un poida facer da que ti dás cando recitas os textos.

-L.P.: Pode ser. Fíxate que hai moita xente que fai lecturas como moi frías para que isto non ocurra, para que o que escoita estea como lendo e non se vexa influído polo que pon o corpo da persoa que está recitando. Pero é que se a persoa que está lendo é a persoa que o escribeu está poñendo cousas aí tamén, ten o seu dereito; lelo é unha forma de escribir, unha forma de incidir sobre o poema e de dar outras opcións que non dás cando dás o libro a ler.

\section{-L.T.: Forma ou contido?}

-L.P.: Forma.

-L.T.: Un pouco contracorrente?

-L.P.: A ver, é moi dificil iso. A min tamén me gusta dicir algo e ter algo que dicir. E se non, calar. Non é que non teña que haber un contido; eu creo que ten que haber un contido, e máis hoxe, que ademais ten que haber un contido até político, forte, duro, pero iso non fai poema. O que fai poema é a forma que sobre iso traballa. É coma cando fas unha escultura, é importante o material, a pedra, claro, pero a pedra soa, é pedra, non é escultura.

-L.T.: Sobre todo nos teus derradeiros traballos, Cativa en su lughar, Tran(n)shumancias, apréciase un discurso máis formalista; é a liña dos traballos que virán?

-L.P.: Sobre todo nos últimos libros, penso que deixei o intimismo; deixeino moi atrás, sabes? O eu non está desa maneira, hai cambios moi profundos. É a liña, pero trato de facer algo moi diferente. Non estou polo labor de repetir libro, odio iso; busco algo que sexa moi distinto, aínda que evite o eu, coma unha poesía máis obxectiva.

-L.T.: Que poetas da literatura galega son obxecto da túa lectura?

-L.P.: Eu valoro cousas moi diferentes unhas das outras, gústame a xente nova que está escribindo. Gústame moito Gonzalo [Hermo], escribe moi ben ese rapaz, moi fino; gústame moito Olalla [Cociña], Branca Novoneyra; gústame Dores Tembrás, pero tamén Pepe Cácamo, é un cacho poeta e é da poesía dos oitenta, que nos queda hoxe como un pouquiño lonxe...

-L.T.: É curioso como para ti os nomes que soan en primeiro lugar son os novos.

-L.P.: Iso ten que ver coa miña profesión, estou segurísima, co ensino, co feito de ter sido profesora; sempre estiven con xente nova. Non sei até que punto é verdade, pero parécemo; a min paréceme que a xente nova é mellor. Mellor de boa persoa, sabes? As persoas vanse cabreando ao longo da vida, vanse enfadando e vanse volvendo un pouquiño rancias. Din cousas e fan cousas que de novos non dicían nin facían. Se estás entre xente nova e te levas ben con ela aprendes moitísimo. A min quedoume que hai que relacionarse coa xente nova, como 
unha vontade de facelo para aprender. Ademais, tiven a grandísima sorte de empezar a escribir con intención de publicar, de descubrir a actitude de poeta despois de coñecer a Luísa Castro, cando ela tiña 18 aniños. E eu tiña 40.

Los versos del Eunuco é un cacho librazo, a min gustoume pola vida. Despois saiu Baleas e Baleas. Eu téñolle unha admiración a Luísa Castro tremenda por eses dous libros sobre todo. Marcoume moito. Até entón, por razóns persoais, escribía para min, para gardalo, para tiralo, sen ningunha confianza.

\section{-L.T.: Coñecíchela persoalmente?}

-L.P.: Moitos anos despois, con moito respeto e con moito medo [risas]. Agora somos íntimas; é unha persoa encantadora, un amor de rapaza.

\section{-L.T.: Foi ao ler o libro dela que dixeches...}

-L.P.: Eu quero escribir isto, eu quero escribir así. Claro, non escribo coma ela para nada, pero tirou de min. E tardei moitísimos anos en dicirllo porque non me atrevía. Era unha admiración tan grande, era unha figura. Coñecina en Alcobendas, dirixindo, con Lupe Grande, o Centro de Estudios de la Poesía de San Sebastián de los Reyes. Viña ela a unha entrevista que lle facía un amigo e viñeron comer á miña casa. Ela era a cousa máis natural e mais sinxela do mundo. Falei con ela e conteille todo, ríase!

\section{-L.T.: Cando empezaches a publicar en galego?}

-L.P.: Con Casa pechada, do 2006. Aí foi onde empecei. Eu creo que sempre escribín en galego, en certa maneira; en galego traducido, algo así. Eu trataba de situarme aquí, neste lugar, aínda que fale doutras cousas moi distintas, o imaxinario é este mundo de aquí. Hai moita tradución, ás veces literal, incluso, un intento de que se vexa detrás o galego. Tiña problemas para escribir en galego porque non estaba en absoluto de acordo coa normativa; sigo estando en contra, como se fixera, moi antisocial, moi pouco considerada coa xente que sempre falara galego.

Non se comprendeu o problema da diglosia, non se comprendeu a fondo, e era o único importante, evitala; e o que fixeron foi acrencentala. Teño unha frase dos primeiros anos, sería nos 80 ou unha cousa así, de meu pai dicindo: «Eses si que falan ben». Unha locutora que fala con acento inglés, non galego, que el non recoñece. Cando eso ocorre, aí pasa algo moi grave. Daquela, outra frase construíuse na miña cabeza e quedou alí, tatuada: «sempre son outros os que falan ben».

O desprezo que sempre houbo do castrapo. $\mathrm{Eu}$ entendo sempre o castrapo como esta lingua da xente das aldeas que cando vai ao médico trata de falar castelán, e non lle sae. Bueno, fálao, dáse a entender, fálao bastante ben... para ser unha lingua estranxeira, fálao moi ben. Se non fala mellor é porque toda a vida falou galego e, por iso mesmo, merece un respecto; copiemos del, que temos moito que aprender. Aprendamos o acento, que non se coidou, considerouse que unha lingua era un léxico; aprendamos a usar os pronomes, aprendamos a fonética, etc. Sorpréndeme moitísimo cando descubro que os rapaces de agora califican de "castrapo" a súa maneira "impura" de falar o galego. Quen lle cambiou o sentido ao termo? Aprenden iso na escola, cando se instrúen na lingua estándar. Así que mira que acertada está a frase aquela: «sempre son outros os que falan ben». Non se podía ensinar o estándar sen despreciar a fala da xente? Así non se acaba coa diglosia, o que sería imprescindible para que o galego non morrese.

-L.T.: Que faltou para que o galego que se fixo se aproximase ao galego que é?

-L.P.: Faltou considerar que a xente que falaba galego de toda a vida non era paleta, era outra cultura. Eu penso que non cambiou moito, que segue habendo unha consideración... Hai pouco unha editora díxome a min: «Home, ben está escribir en galego e en galego rural, pero esa cousa así enxebre hai que deixala». Que entende por cousa enxebre? O acento? que é o que entende? Así era falando.

-L.T.: Hai quen pensa que habería que ir deixando de escribir tanto sobre a Terra, ti que opinas?

-L.P.: A poesía ten que ser libre. A poesía non é poesía porque fales desto ou daquelo, é poesía se é poesía. E xa está. Cando ti escribes, tes que saír, tes que escribir do que che sae de dentro, tes que situarte naquel lugar desde o cal poidas dicir algo, aportar algo. Se o que che sae de dentro é falar da terra, será porque dalgunha forma estás condicionada. Se eu falo da terra non é casualidade: gastei todos os cartos que tiña en restaurar esta casa, en pasar un verán aquí, encerrada nestas catro paredes, onde a xente coa que falo, na súa lingua de toda a vida, é a xente de aquí, coa que fun á escola. 
Porque non me van deixar falar da terra, que mal ten? Eu non me meto con eles porque escriban do que queiran.

Por que pasei a Casa Pechada falando en galego? Sentía que había que romper con iso e deixar atrás o resentimento. Era, son, unha resentida, téñoo moi claro. Quen sofre por falar unha lingua non esquece facilmente. É moi duro sufrir por falar e eu medrei nun tempo en que iso era a norma. E fíxeno, escribir en galego. Pero fíxeno sen ningún convecemento. Fíxeno porque había que facelo, porque eu dicía, non é que non se poida escribir así, claro que podo escribir así se quero, vale? E empecei tamén a ler en galego, que non lía. Negábame a ler ese galego. Nin Rosalía nin Castelao nin Curros precisaran do estándar. Fíxeno, pero despois entendín que de aí había que pasar a outra cousa.

\section{-L.T.: Cativa en su lughar?}

-L.P.: Cativa en su lughar. É unha versión de Casa Pechada en castrapo, un experimento co castelán contaminado de Galicia como lingua de fronteira, que me permitía traducir aquela poesía de Casa pechada, cousa que non me pasaba cun rexistro académico. Os poemas cambian en moitísimos sentidos. É unha creación case de novo.

-L.T.: No teu último libro, Tra(n)shumancias, tamén apostas por un un discurso, en certa maneira, híbrido. Ten, isto que ver coa túa experiencia vital, co feito de vivir en Madrid?

-L.P.: Creo que é moi importante, si. Estás lonxe e a mirada non está condicionada polo que estás oíndo todos os días. É moito máis fácil ser crítico con distancia.

-L.T.: Sentes que Tra(n)shumancias foi un libro de tránsito? Refírome ao contido. Incitábame a pensar que era un lugar no que permanecerías só mentres o escribises. Poida que agora esteas facendo poesía desde outro lugar.

-L.P.: Chámase Tra(n)shumancias, sería tamén bonito pensar que é un paso de aquí para alá, pode ser... O que estou escribindo agora é máis arriscado nun sentido e menos noutro. É unha lingua máis uniforme, perfectamente galega, pero de aquí. É un libro dialectal a tope. Non sei cal vai ser o título, pero podería ser "Co co co co u".

\section{lingua?}

-L.P.: Non teño que recreala, está.

-L.T.: Á hora de publicar cousas así, tan arriscadas, sentícheste escoitada?

-L.P.: Pánico. En Madrid non tanto, pero cando cheguei a Santiago ao Modus Vivendi para ler Cativa, sentía pánico, tremía de arriba a abaixo. Cando lin o primeiro poema en castrapo, a xente que estaba escoitando riu un pouquiño, pensaba que ía de coña, para que nos riramos todos un pouco. Empezou a calar, empezou a entrar, entrar, entrar e, ao final, a xente estaba absolutamente metida. E teño que recoñecer que en certo sector da poesía galega o libro foi moi ben recibido. Hai outro sector, claro, lóxico.

-L.T.: Como é publicar un libro "híbrido" nunha editora de fóra? Imaxino que haberá que dicirlles que hai palabras en galego, que non che cambien cousas...

-L.P.: Todo o contrario, este libro pedíronmo a partir de Cativa. Eu non fun buscando a editorial, non o sei facer e ademais dáme moitísimo medo e moita vergoña. Pedíronmo así, non estaba terminado e non sabían o que ía haber. Cando Nuria Ruíz de Viñaspre me dixo que quería un libro meu, díxenlle que tiña un a medias, e ademais medio en galego medio en castelán, e dixo: no me importa. Mais, eu sei que Nuria é unha editora que lle gusta como escribo e ela é poeta; entende e gustoulle moito a obra anterior.

-L.T.: Que experiencia tes da túa participación en eMe, unha colección de poesía escrita por mulleres?

-L.P.: Moi agradable. Somos xente moi diferente, escribimos de forma moi distinta e ímonos coñecendo bastante, fas amizade. Esas presentacións, máis que nada xa son encontros, descubres aspectos que non coñecías... a min gústame.

\section{tos á vez?}

-L.T.: E agora, estás con varios proxec-

-L.P.: Estou. A novela está aí sempre. É que é un rollo. Non sei se sairá. Estou traballando moito coa voz da protagonista, que non me gusta. Logo, este poemario novo co que estou, que non vai ser un libro grande, vai ser un libriño, sairá bilingüe e vaino traducir Ángela Segovia a un castelán antinormativo. Ángela está creando unha editorial e vaino sacar alí; chámase Paisana.

-L.T.: Parece que o tempo é unha das cousas que máis valoras. 
-L.P.: Si, o meu tempo, o tempo para min. Non podería vivir sen eses momentos, iso téñoo moi claro. Sabes que teño un problema de visión moi serio? Teño un principio de dexeneración da mácula asociada á idade; teño que ter as cousas moi enfronte e como moi enfocadas, cunha luz moi forte. Isto asústame, ves? A idea de non poder escribir, de non ver para ler. Das dúas cousas, creo que podería pasar sen esta última. Mal, pero podería. Ademais, sempre habería alguén, un neto ou alguén, que o faga por min. Mentres que escribir...

-L.T.: Aínda así, es unha muller moi forte, con poucos medos.

-L.P.: Non teño moitos, pero a idea de non poder disfrutar das cousas que me gustan, iso tortúrame moito. Non o penso moito e xa está.

-L.T.: Para ir dando cabo a esta conversa, que lle preguntarías ao futuro?
-L.P.: [risas] Penso que non hai que preguntarlle nada, hai que vivir o o presente; que lle vas preguntar?

-L.T.: Pois, dito doutro xeito. Nos seguintes dez anos, onde che gustaría estar?

-L.P.: Quero que me deixen tempo para estar aquí, unha semaniña cada mes, que é dificil, vir recoller as noces, vir recoller as mazás, todos os anos, moitos anos, que non me caia unha figueira encima; e que máis? Pouco máis.

-L.T.: Pídeslle unha casa ao futuro?

-L.P.: Unha casiña. Que me deixe estar na miña casa con algo de saúde e cando estea moi mal que haxa unha persoa, así, arriscada, que saiba facer poesía e que me axude a facer a liquidación final.

-L.T.: Non che ha faltar.

-L.P.: Penso que non é tan doadiño eso. ha faltar.
-L.T.: Haberá que buscala, pero non che 